\title{
Comprehensive comparison of the delta- and wye-connected autotransformer applied to 12-pulse rectifier
}

\author{
Fangang MENG $^{1}$, Lei GAO ${ }^{1}$, Wei YANG ${ }^{1}$, Shiyan YANG ${ }^{1}$
}

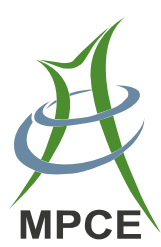

\begin{abstract}
12-pulse rectifier is extensively used in high power rectification, and the delta-connected autotransformer and wye-connected autotransformer are its two most popular phase-shift transformers. This paper compares the 12-pulse rectifiers using the two transformers via calculating the input line current, load voltage, $\mathrm{kVA}$ ratings of the two autotransformer, $\mathrm{kVA}$ ratings of the auxiliary magnetic devices. From the viewpoint of power quality of AC mains and DC side, the two 12-pulse rectifiers are the same. The kVA rating of the IPR in the two 12-pulse rectifiers are equal, and the $\mathrm{kVA}$ rating of the ZSBT in the two 12-pulse rectifier are also equal to each other, under the same load power. However, the kVA of the deltaconnected autotransformer is less than that of the wyeconnected autotransformer under the same load power. Some experimental results are shown to validate the correctness of the theoretical analysis.
\end{abstract}

Keywords Multi-pulse rectifier (MPR), Delta-connected autotransformer, Wye-connected autotransformer, kVA

CrossCheck date: 29 December 2015

Received: 23 July 2015 / Accepted: 1 January 2016/Published online: 19 January 2016

(C) The Author(s) 2016. This article is published with open access at Springerlink.com

$\triangle$ Fangang MENG

mfg0327@sina.com

Lei GAO

hualeier111@126.com

Wei YANG

yangv@hit.edu.cn

Shiyan YANG

syyang@hit.edu.cn

1 Department of Electrical Engineering and Automation, Harbin Institute of Technology, Harbin, China rating, Inter-phase reactor (IPR), Zero-sequence blocking transformer (ZSBT)

\section{Introduction}

Because of its simple system configuration, low EMI at input ac mains and reduced voltage rippled dc side, multipulse rectifier (MPR) is widely used in adjustable speed drives, electro-chemical processes, aircraft converter systems and renewable energy conversion systems [1-6]. A MPR comprises a phase-shifting transformer and several three-phase diode bridge rectifiers, where the harmonics generated by one rectifier can be cancelled by other rectifiers [7]. The phase-shifting transformer produces a set of $3 \mathrm{~N}$-phase voltages with proper phase-shift angle to feed the three-phase diode bridge rectifiers [8]. Therefore, the phase-shifting transformer is the necessary device in MPR.

Generally, the phase-shifting transformer can be classified into two types. One is the isolated transformer, and another is the autotransformer [9-14]. Compared with the isolated transformer, the windings in auto-connected transformer are inter-connected. Therefore, the auto-connected transformer has lower kVA rating than that of the isolated transformer [13]. When the difference between the input and output voltages are not much, the auto-connected transformer is suitable to be a phase-shifting transformer in MPR. There are lots of different winding connections about auto-connected transformer, such as the delta-connection, wye-connection, polygon-connection, T-connection, and the fork-connection [1].

In MPRs, the phase-shifting transformer determines the power density of the rectifier. Among the auto-connected transformers, the transformer used in the 12-pulse rectifier 
has the highest power density. The six-phase delta- and wye-connected autotransformers are the most popular in 12-pulse rectifier. Therefore, it is meaningful to compare the delta- and wye-connected autotransformers. In this paper, we compare the two autotransformers from the input line current, load voltage, kVA rating under the same output power. Some simulations and experiments are carried out to validate the theoretical analysis.

\section{Input line currents and load voltage of 12-pulse rectifier}

Figure 1 shows the 12-pulse rectifier using autotransformer. The autotransformer is used to produce two sets of three-phase voltages with $30^{\circ}$ phase-shift. The function of the IPR (IPR: Inter-phase Reactor) is to absorb the output voltage difference of two bridge rectifiers, which can ensure the independent operation of the two bridge rectifiers. The ZSBT (Zero-sequence Blocking Transformer) exhibits high impedance to zero-sequence currents, which is used to promote $120^{\circ}$ conduction for each rectifier diode [5].

Figure 2 shows the winding connection of delta-connected autotransformer and its phase diagram.

In Fig. $2 \mathrm{a}, N_{\Delta}$ is the turn numbers of the delta-connected winding, and $N_{\mathrm{q} \Delta}$ is the turn numbers of the extended winding of the autotransformer.

Figure 3 illustrates the winding connection of wyeconnected autotransformer and its phase diagram.

In Fig. 3a, $N_{\mathrm{Y}}$ is the turn numbers of the wye-connected winding, and $N_{Y \Delta}$ is the turn numbers of the extended winding of the autotransformer.

From Fig. 2, the relation between the turn numbers of the delta-connected autotransformer meet

$\frac{N_{\Delta}}{N_{\mathrm{q} \Delta}}=\frac{\sqrt{3}}{2-\sqrt{3}}$

From Fig. 3, the relation between the turn numbers of the wye-connected autotransformer meet

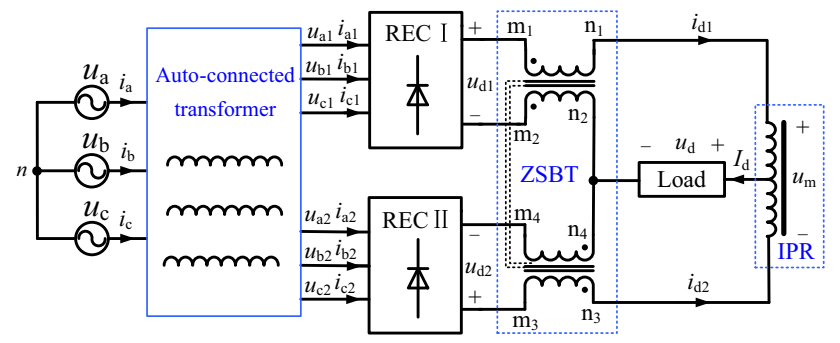

Fig. 1 12-pulse rectifier using auto-connected transformer

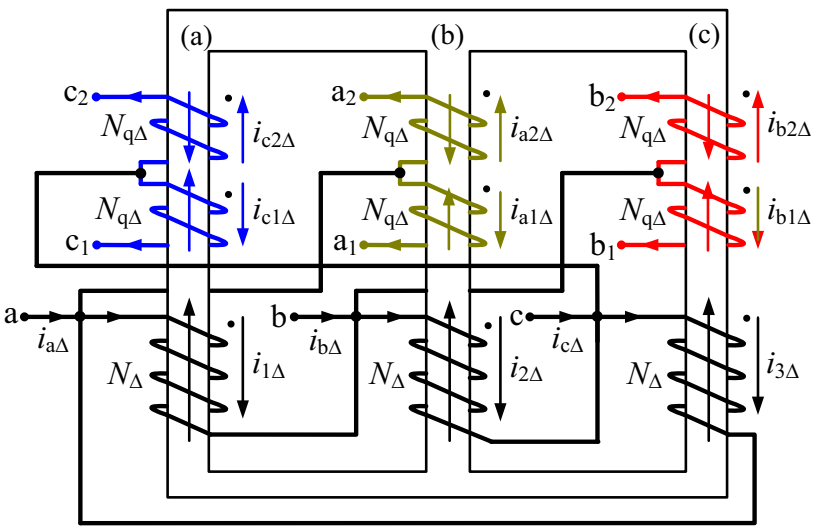

(a) Winding connection of delta-connected autotransformer

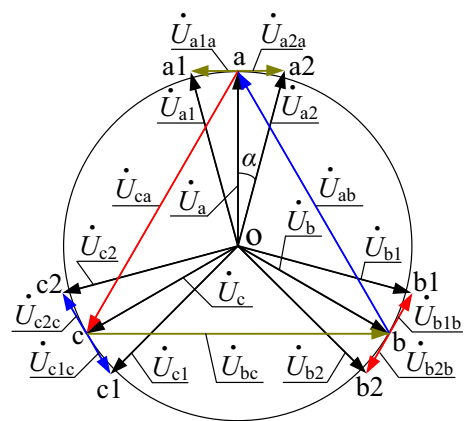

(b) Phase diagram

Fig. 2 Winding connection of delta-connected autotransformer and its phase diagram

$\frac{N_{\mathrm{Y}}}{N_{\mathrm{qY}}}=2+\sqrt{3}$

Assume the three-phase input phase voltage as

$\left\{\begin{array}{l}u_{\mathrm{a}}=\sqrt{2} U_{\mathrm{m}} \sin \omega t \\ u_{\mathrm{b}}=\sqrt{2} U_{\mathrm{m}} \sin \left(\omega t-120^{\circ}\right) \\ u_{\mathrm{c}}=\sqrt{2} U_{\mathrm{m}} \sin \left(\omega t+120^{\circ}\right)\end{array}\right.$

From Fig. 2b, the two sets of three-phase output voltages of the delta-connected autotransformer are calculated as

$\left\{\begin{array}{l}u_{\mathrm{a} 1 \Delta}=\sqrt{2} U_{\mathrm{n} \Delta} \sin \left(\omega t+15^{\circ}\right) \\ u_{\mathrm{b} 1 \Delta}=\sqrt{2} U_{\mathrm{n} \Delta} \sin \left(\omega t-105^{\circ}\right) \\ u_{\mathrm{c} 1 \Delta}=\sqrt{2} U_{\mathrm{n} \Delta} \sin \left(\omega t+135^{\circ}\right) \\ u_{\mathrm{a} 2 \Delta}=\sqrt{2} U_{\mathrm{n} \Delta} \sin \left(\omega t-15^{\circ}\right) \\ u_{\mathrm{b} 2 \Delta}=\sqrt{2} U_{\mathrm{n} \Delta} \sin \left(\omega t-135^{\circ}\right) \\ u_{\mathrm{c} 2 \Delta}=\sqrt{2} U_{\mathrm{n} \Delta} \sin \left(\omega t+105^{\circ}\right)\end{array}\right.$

where $U_{\mathrm{n} \Delta}=(\sqrt{6}-\sqrt{2}) U_{\mathrm{m}}$.

From Fig. 3b, the two sets of three-phase output voltages of the wye-connected autotransformer are calculated as 


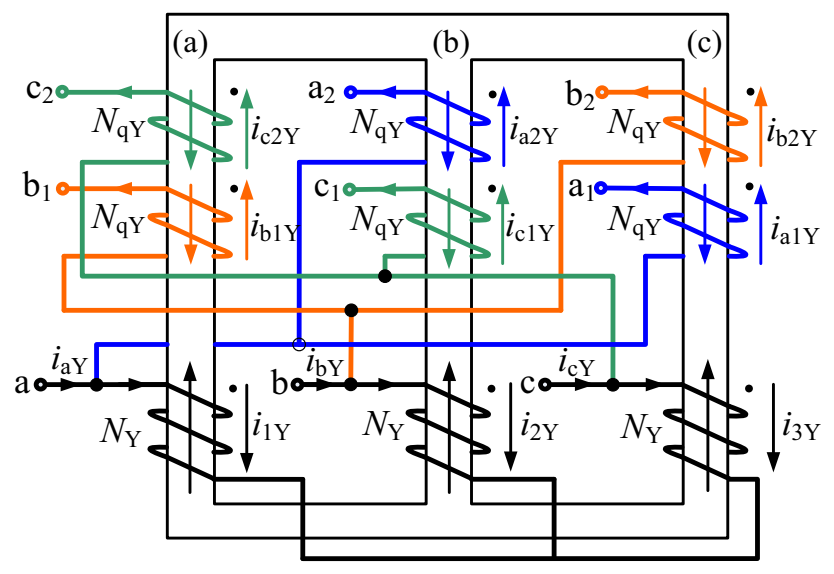

(a) Winding connection of wye-connected autotransformer

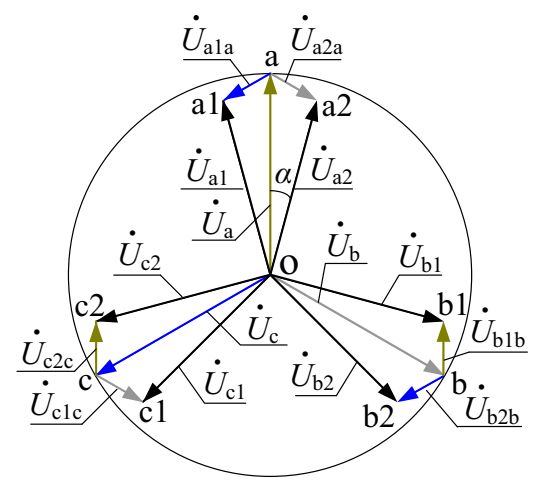

(b) Phase diagram

Fig. 3 Winding connection of wye-connected autotransformer and its phase diagram

$$
\left\{\begin{array}{l}
u_{\mathrm{a} 1 \mathrm{Y}}=\sqrt{2} U_{\mathrm{nY}} \sin \left(\omega t+15^{\circ}\right) \\
u_{\mathrm{b} 1 \mathrm{Y}}=\sqrt{2} U_{\mathrm{nY}} \sin \left(\omega t-105^{\circ}\right) \\
u_{\mathrm{c} 1 \mathrm{Y}}=\sqrt{2} U_{\mathrm{nY}} \sin \left(\omega t+135^{\circ}\right) \\
u_{\mathrm{a} 2 \mathrm{Y}}=\sqrt{2} U_{\mathrm{nY}} \sin \left(\omega t-15^{\circ}\right) \\
u_{\mathrm{b} 2 \mathrm{Y}}=\sqrt{2} U_{\mathrm{nY}} \sin \left(\omega t-135^{\circ}\right) \\
u_{\mathrm{c} 2 \mathrm{Y}}=\sqrt{2} U_{\mathrm{nY}} \sin \left(\omega t+105^{\circ}\right)
\end{array}\right.
$$

where $U_{\mathrm{nY}}=\sqrt{6}(\sqrt{3}-1) U_{\mathrm{m}} / 2$.

From (4) and (5), it is obtained that the delta-connected autotransformer operating under step up condition, and the wye-connected autotransformer operating under step down condition.

In addition, from (4), (5) and Fig. 1, it is also obtained that the switching functions of the 12-pulse rectifier with delta-connected autotransformer are the same with that of the 12-pulse rectifier with wye-connected autotransformer, that is
$\left\{\begin{array}{l}S_{\mathrm{a} 1 \Delta}=S_{\mathrm{a} 1 \mathrm{Y}} \\ S_{\mathrm{b} 1 \Delta}=S_{\mathrm{b} 1 \mathrm{Y}} \\ S_{\mathrm{c} 1 \Delta}=S_{\mathrm{c} 1 \mathrm{Y}} \\ S_{\mathrm{a} 2 \Delta}=S_{\mathrm{a} 2 \mathrm{Y}} \\ S_{\mathrm{b} 2 \Delta}=S_{\mathrm{b} 2 \mathrm{Y}} \\ S_{\mathrm{c} 2 \Delta}=S_{\mathrm{c} 2 \mathrm{Y}}\end{array}\right.$

where $S_{\mathrm{a} 1 \triangle}, S_{\mathrm{a} 2 \triangle}, S_{\mathrm{b} 1 \triangle}, S_{\mathrm{b} 2 \triangle}, S_{\mathrm{c} 1 \triangle}, S_{\mathrm{c} 2 \triangle}$ are the switching functions of phases a1, a2, b1, b2, c1, c2 in the 12-pulse rectifier with delta-connected autotransformer, respectively; $S_{\mathrm{a} 1 \mathrm{Y}}, S_{\mathrm{a} 2 \mathrm{Y}}, S_{\mathrm{b} 1 \mathrm{Y}}, S_{\mathrm{b} 2 \mathrm{Y}}, S_{\mathrm{c} 1 \mathrm{Y}}, S_{\mathrm{c} 2 \mathrm{Y}}$ are the switching functions of phases a1, a2, b1, b2, c1, c2 in the 12-pulse rectifier with wye-connected autotransformer.

From (4), the switching function $S_{\mathrm{a} 1 \triangle}$ can be derived, as illustrated in Fig. 4.

The relation between the switching functions meets

$$
\left\{\begin{array}{l}
S_{\mathrm{a} 1 \Delta}=S_{\mathrm{a} 1 \mathrm{Y}} \\
S_{\mathrm{b} 1 \Delta}=S_{\mathrm{b} 1 \mathrm{Y}}=S_{\mathrm{a} 1 \Delta} \angle-120^{\circ} \\
S_{\mathrm{c} 1 \Delta}=S_{\mathrm{c} 1 \mathrm{Y}}=S_{\mathrm{a} 1 \Delta} \angle+120^{\circ} \\
S_{\mathrm{a} 2 \Delta}=S_{\mathrm{a} 2 \mathrm{Y}}=S_{\mathrm{a} 1 \Delta} \angle-30^{\circ} \\
S_{\mathrm{b} 2 \Delta}=S_{\mathrm{b} 2 \mathrm{Y}}=S_{\mathrm{b} 1 \Delta} \angle-30^{\circ} \\
S_{\mathrm{c} 2 \Delta}=S_{\mathrm{c} 2 \mathrm{Y}}=S_{\mathrm{c} 1 \Delta} \angle-30^{\circ}
\end{array}\right.
$$

\subsection{Input line current}

In Fig. 2a, when using the delta-connected autotransformer, from the ampere-turn balance law, the three-phase input line currents are expressed as

$$
\left\{\begin{array}{l}
i_{\mathrm{a} \Delta}=i_{1 \Delta}-i_{3 \Delta}+i_{\mathrm{a} 1 \Delta}+i_{\mathrm{a} 2 \Delta} \\
i_{\mathrm{b} \Delta}=i_{2 \Delta}-i_{1 \Delta}+i_{\mathrm{b} 1 \Delta}+i_{\mathrm{b} 2 \Delta} \\
i_{\mathrm{c} \Delta}=i_{3 \Delta}-i_{2 \Delta}+i_{\mathrm{c} 1 \Delta}+i_{\mathrm{c} 2 \Delta}
\end{array}\right.
$$

and from Kirchhoff's current law, it is obtained that

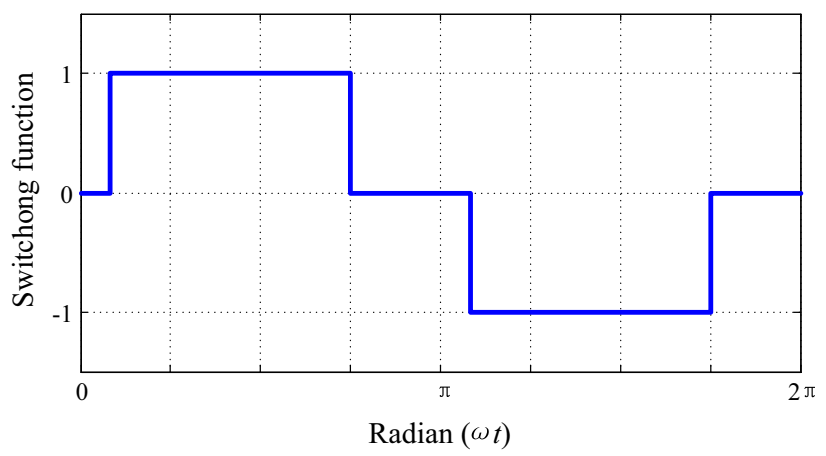

Fig. 4 Switching function of $S_{\mathrm{a} 1 \triangle}$ 
$\left\{\begin{array}{l}N_{\Delta} i_{1 \Delta}=N_{\mathrm{q} \Delta}\left(i_{\mathrm{c} 2 \Delta}-i_{\mathrm{c} 1 \Delta}\right) \\ N_{\Delta} i_{2 \Delta}=N_{q \Delta}\left(i_{\mathrm{a} 2 \Delta}-i_{\mathrm{a} 1 \Delta}\right) \\ N_{\Delta} i_{3 \Delta}=N_{q \Delta}\left(i_{\mathrm{b} 2 \Delta}-i_{\mathrm{b} 1 \Delta}\right)\end{array}\right.$

From (1), (7) and (8), the input line current is calculated as

$\left\{\begin{array}{l}i_{\mathrm{a} \Delta}=i_{\mathrm{a} 1 \Delta}+i_{\mathrm{a} 2 \Delta}+\frac{2-\sqrt{3}}{\sqrt{3}}\left(i_{\mathrm{c} 2 \Delta}-i_{\mathrm{b} 2 \Delta}+i_{\mathrm{b} 1 \Delta}-i_{\mathrm{c} 1 \Delta}\right) \\ i_{\mathrm{b} \Delta}=i_{\mathrm{b} 1 \Delta}+i_{\mathrm{b} 2 \Delta}+\frac{2-\sqrt{3}}{\sqrt{3}}\left(i_{\mathrm{a} 2 \Delta}-i_{\mathrm{c} 2 \Delta}+i_{\mathrm{c} 1 \Delta}-i_{\mathrm{a} 1 \Delta}\right) \\ i_{\mathrm{c} \Delta}=i_{\mathrm{c} 1 \Delta}+i_{\mathrm{c} 2 \Delta}+\frac{2-\sqrt{3}}{\sqrt{3}}\left(i_{\mathrm{b} 2 \Delta}-i_{\mathrm{a} 2 \Delta}+i_{\mathrm{a} 1 \Delta}-i_{\mathrm{b} 1 \Delta}\right)\end{array}\right.$

When the load is large inductive, the load current is viewed to be constant. Therefore, the output currents of the two diode bridge rectifiers are calculated as

$i_{\mathrm{d} 1}=i_{\mathrm{d} 2}=\frac{1}{2} I_{\mathrm{d}}$

From Fig. 1, the input currents of the two diode bridge rectifiers is calculated as

$\left\{\begin{array}{l}i_{\mathrm{a} 1}=S_{\mathrm{a} 1 \Delta} i_{\mathrm{d} 1}=S_{\mathrm{a} 1 \mathrm{Y}} i_{\mathrm{d} 1} \\ i_{\mathrm{b} 1}=S_{\mathrm{b} 1 \Delta} i_{\mathrm{d} 1}=S_{\mathrm{b} 1 \mathrm{Y}} i_{\mathrm{d} 1} \\ i_{\mathrm{c} 1}=S_{\mathrm{c} 1 \Delta} i_{\mathrm{d} 1}=S_{\mathrm{c} 1 \mathrm{Y}} i_{\mathrm{d} 1} \\ i_{\mathrm{a} 2}=S_{\mathrm{a} 2 \Delta} i_{\mathrm{d} 2}=S_{\mathrm{a} 2 \mathrm{Y}} i_{\mathrm{d} 2} \\ i_{\mathrm{b} 2}=S_{\mathrm{b} 2 \Delta} i_{\mathrm{d} 2}=S_{\mathrm{b} 2 \mathrm{Y}} i_{\mathrm{d} 2} \\ i_{\mathrm{c} 2}=S_{\mathrm{c} 2 \Delta} i_{\mathrm{d} 2}=S_{\mathrm{c} 2 \mathrm{Y}} i_{\mathrm{d} 2}\end{array}\right.$

Substituting (11) into (9) yields

$\left\{\begin{array}{l}i_{\mathrm{a} \Delta}=\frac{1}{2} I_{\mathrm{d}}\left[S_{\mathrm{a} 1 \Delta}+S_{\mathrm{a} 2 \Delta}+\frac{2-\sqrt{3}}{\sqrt{3}}\left(S_{\mathrm{c} 2 \Delta}-S_{\mathrm{b} 2 \Delta}+S_{\mathrm{b} 1 \Delta}-S_{\mathrm{c} 1 \Delta}\right)\right] \\ i_{\mathrm{b} \Delta}=\frac{1}{2} I_{\mathrm{d}}\left[S_{\mathrm{b} 1 \Delta}+S_{\mathrm{b} 2 \Delta}+\frac{2-\sqrt{3}}{\sqrt{3}}\left(S_{\mathrm{a} 2 \Delta}-S_{\mathrm{c} 2 \Delta}+S_{\mathrm{c} 1 \Delta}-S_{\mathrm{a} 2 \Delta}\right)\right] \\ i_{\mathrm{c} \Delta}=\frac{1}{2} I_{\mathrm{d}}\left[S_{\mathrm{c} 1 \Delta}+S_{\mathrm{c} 2 \Delta}+\frac{2-\sqrt{3}}{\sqrt{3}}\left(S_{\mathrm{b} 2 \Delta}-S_{\mathrm{a} 2 \Delta}+S_{\mathrm{a} 2 \Delta}-S_{\mathrm{b} 1 \Delta}\right)\right]\end{array}\right.$

To set $i_{\mathrm{a} \Delta}$ as an example, the Fourier series Expansion of $i_{\mathrm{a} \Delta}$ can calculated as

$i_{\mathrm{a} \Delta}=\frac{2 \sqrt{6}(\sqrt{3}-1)}{\pi} I_{\mathrm{d}}\left[\sin (\omega t)-\sum_{k=1}^{\infty} \frac{\sin (12 k \pm 1) \omega t}{12 k \pm 1}\right]$

Similarly, in Fig. 3a, from the ampere-turn balance law, it is obtained that
$\left\{\begin{array}{l}N_{\mathrm{qY}} i_{\mathrm{c} 2 \mathrm{Y}}+N_{\mathrm{qY}} i_{\mathrm{b} 1 \mathrm{Y}}=N_{\mathrm{Y}} i_{1 \mathrm{Y}} \\ N_{\mathrm{qY}} i_{\mathrm{a} 2 \mathrm{Y}}+N_{\mathrm{qY}} i_{\mathrm{c} 1 \mathrm{Y}}=N_{\mathrm{Y}} i_{2 \mathrm{Y}} \\ N_{\mathrm{qY}} i_{\mathrm{b} 2 \mathrm{Y}}+N_{\mathrm{qY}} i_{\mathrm{a} 1 \mathrm{Y}}=N_{\mathrm{Y}} i_{3 \mathrm{Y}}\end{array}\right.$

and from Kirchhoff's current law, it is obtained that

$\left\{\begin{array}{l}i_{\mathrm{aY}}=i_{1 \mathrm{Y}}+i_{\mathrm{a} 1 \mathrm{Y}}+i_{\mathrm{a} 2 \mathrm{Y}} \\ i_{\mathrm{bY}}=i_{2 \mathrm{Y}}+i_{\mathrm{b} 1 \mathrm{Y}}+i_{\mathrm{b} 2 \mathrm{Y}} \\ i_{\mathrm{cY}}=i_{3 \mathrm{Y}}+i_{\mathrm{c} 1 \mathrm{Y}}+i_{\mathrm{c} 2 \mathrm{Y}}\end{array}\right.$

From (2), (14) and (15), the input line currents are calculated as

$\left\{\begin{array}{l}i_{\mathrm{aY}}=(2-\sqrt{3})\left(i_{\mathrm{b} 1 \mathrm{Y}}+i_{\mathrm{c} 2 \mathrm{Y}}\right)+i_{\mathrm{a} 1 \mathrm{Y}}+i_{\mathrm{a} 2 \mathrm{Y}} \\ i_{\mathrm{bY}}=(2-\sqrt{3})\left(i_{\mathrm{c} 1 \mathrm{Y}}+i_{\mathrm{a} 2 \mathrm{Y}}\right)+i_{\mathrm{b} 1 \mathrm{Y}}+i_{\mathrm{b} 2 \mathrm{Y}} \\ i_{\mathrm{cY}}=(2-\sqrt{3})\left(i_{\mathrm{a} 1 \mathrm{Y}}+i_{\mathrm{b} 2 \mathrm{Y}}\right)+i_{\mathrm{c} 1 \mathrm{Y}}+i_{\mathrm{c} 2 \mathrm{Y}}\end{array}\right.$

Substituting (10) and (11) into (16) yields

$\left\{\begin{array}{l}i_{\mathrm{a} Y}=\frac{1}{2} I_{\mathrm{d}}\left[(2-\sqrt{3})\left(S_{\mathrm{b} 1 \mathrm{Y}}+S_{\mathrm{c} 2 \mathrm{Y}}\right)+S_{\mathrm{a} 1 \mathrm{Y}}+S_{\mathrm{a} 2 \mathrm{Y}}\right] \\ i_{\mathrm{bY}}=\frac{1}{2} I_{\mathrm{d}}\left[(2-\sqrt{3})\left(S_{\mathrm{c} 1 \mathrm{Y}}+S_{\mathrm{a} 2 \mathrm{Y}}\right)+S_{\mathrm{b} 1 \mathrm{Y}}+S_{\mathrm{b} 2 \mathrm{Y}}\right] \\ i_{\mathrm{cY}}=\frac{1}{2} I_{\mathrm{d}}\left[(2-\sqrt{3})\left(S_{\mathrm{a} 1 \mathrm{Y}}+S_{\mathrm{b} 2 \mathrm{Y}}\right)+S_{\mathrm{c} 1 \mathrm{Y}}+S_{\mathrm{c} 2 \mathrm{Y}}\right]\end{array}\right.$

To set $i_{\mathrm{aY}}$ as an example, the Fourier series Expansion of $i_{\mathrm{aY}}$ can calculated as

$i_{\mathrm{aY}}=\frac{3 \sqrt{6}(\sqrt{3}-1)}{2 \pi} I_{\mathrm{d}}\left[\sin (\omega t)-\sum_{k=1}^{\infty} \frac{\sin (12 k \pm 1) \omega t}{12 k \pm 1}\right]$

Figure 5a shows the input line current $i_{\mathrm{a} \Delta}$, and Fig. $5 \mathrm{~b}$ shows the input line current $i_{\mathrm{aY}}$, and Fig. 5c shows their spectrum.

From (13), (18), and Fig. 5, the following conclusions are obtained:

1) Under the same load current, when using the deltaconnected autotransformer, the input line current is greater than that of using the wye-connected autotransformer, and the RMS ratio of the current $i_{\mathrm{a} \Delta}$ to current $i_{\mathrm{aY}}$ is $4 / 3$.

2) The THD values of the two currents are equal to each other, and the spectrums of the two currents are the same.

\subsection{Load voltage}

From Fig. 1, when using the delta-connected autotransformer, the load voltage can be presented as 


$$
\begin{aligned}
u_{\mathrm{d} \Delta} & =v_{\mathrm{Mn} \Delta}-v_{\mathrm{Nn} \Delta}=\frac{1}{2}\left(v_{\mathrm{m} 1 \mathrm{n} \Delta}-v_{\mathrm{m} 2 \mathrm{n} \Delta}\right)+\frac{1}{2}\left(v_{\mathrm{m} 3 \mathrm{n} \Delta}-v_{\mathrm{m} 4 \mathrm{n} \Delta}\right) \\
& =\frac{1}{2}\left(u_{\mathrm{d} 1 \Delta}+u_{\mathrm{d} 2 \Delta}\right)
\end{aligned}
$$

The output voltages of the two diode bridge rectifiers can be derived from the modulation theory

$\left\{\begin{array}{l}u_{\mathrm{d} 1 \Delta}=S_{\mathrm{a} 1 \Delta} u_{\mathrm{a} 1 \Delta}+S_{\mathrm{b} 1 \Delta} u_{\mathrm{b} 1 \Delta}+S_{\mathrm{c} 1 \Delta u_{\mathrm{c} 1 \Delta}} \\ u_{\mathrm{d} 2 \Delta}=S_{\mathrm{a} 2 \Delta} u_{\mathrm{a} 2 \Delta}+S_{\mathrm{b} 2 \Delta} u_{\mathrm{b} 2 \Delta}+S_{\mathrm{c} 2 \Delta} u_{\mathrm{c} 2 \Delta}\end{array}\right.$

From (3), (4) and (20), the load voltage $u_{\mathrm{d} \Delta}$ is calculated as

$u_{\mathrm{d} \Delta}= \begin{cases}\sqrt{6} U_{\mathrm{m}} \cos \left(\omega t-\frac{k \pi}{6}\right) & {\left[\frac{k \pi}{6}, \frac{k \pi}{6}+\frac{\pi}{12}\right]} \\ \sqrt{6} U_{\mathrm{m}} \cos \left(\omega t-\frac{\pi}{6}-\frac{k \pi}{6}\right) & {\left[\frac{k \pi}{6}+\frac{\pi}{12}, \frac{k \pi}{6}+\frac{2 \pi}{12}\right]}\end{cases}$

Similarly, when using the wye-connected autotransformer, the load voltage is calculated as

$u_{\mathrm{d} Y}= \begin{cases}\frac{3 \sqrt{2}}{2} U_{\mathrm{m}} \cos \left(\omega t-\frac{k \pi}{6}\right) & {\left[\frac{k \pi}{6}, \frac{k \pi}{6}+\frac{\pi}{12}\right]} \\ \frac{3 \sqrt{2}}{2} U_{\mathrm{m}} \cos \left(\omega t-\frac{\pi}{6}-\frac{k \pi}{6}\right) & {\left[\frac{k \pi}{6}+\frac{\pi}{12}, \frac{k \pi}{6}+\frac{2 \pi}{12}\right]}\end{cases}$

Figure 6 shows the load voltages $u_{\mathrm{d} \Delta}$ and $u_{\mathrm{dY}}$.

From (21), (22) and Fig. 6, when using the delta-connected autotransformer, the load voltage is greater than that of using the wye-connected autotransformer under the same input voltages.

\section{$3 \mathrm{kVA}$ ratings of delta-connected autotransformer and wye-connected autotransformer}

The phase-shifting transformer is the main magnetic device in a MPR, which determines the power density of the system. Therefore, it is meaningful to compare the kVA ratings of the two autotransformers under the same load power.

In order to calculate the kVA rating of the autotransformer, it is necessary to calculate the voltages across and currents through the windings of the autotransformer.

\section{1 kVA rating of delta-connected autotransformer}

From Fig. 2, the voltage across the delta-connected winding is equal to the input line-to-line voltage, and its

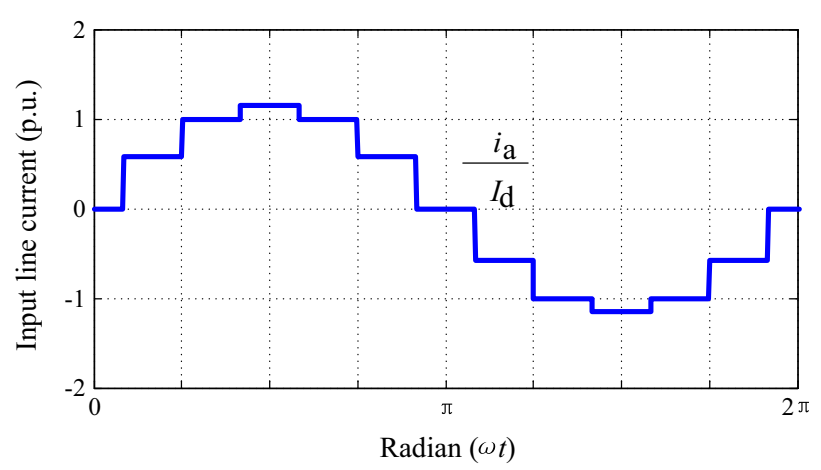

(a) Input line current $i_{\mathrm{a} \Delta}$

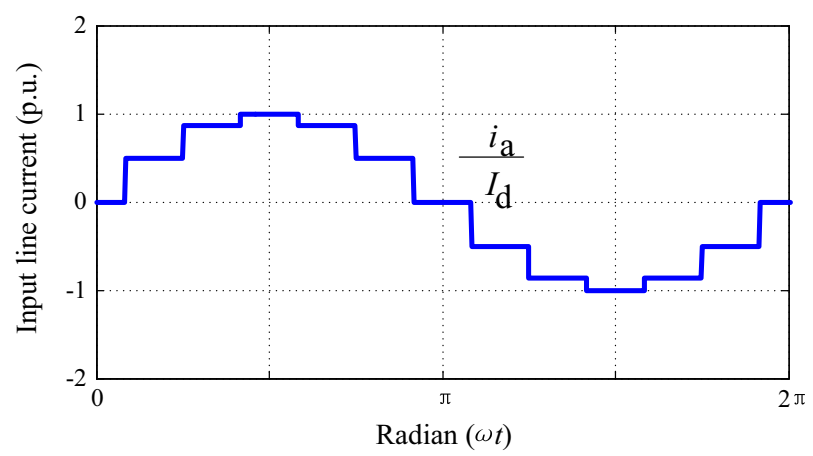

(b) Input line current $i_{\mathrm{aY}}$

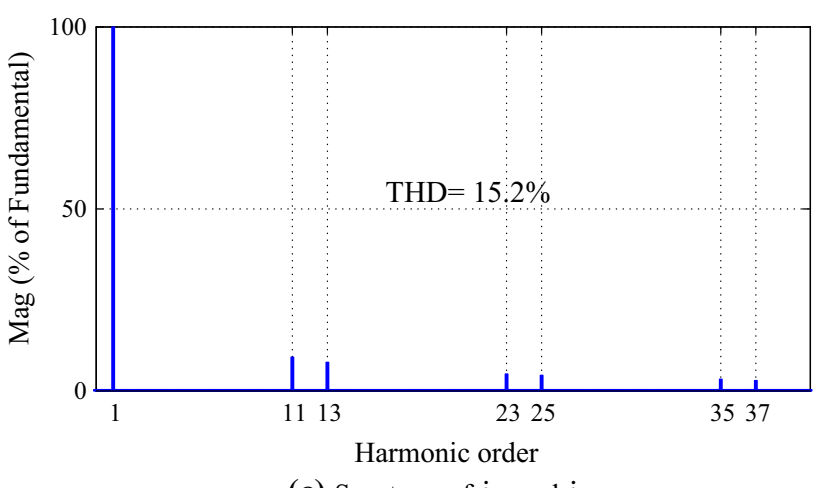

(c) Spectrum of $i_{\mathrm{a} \Delta}$ and $i_{\mathrm{aY}}$

Fig. 5 Input line currents of the two 12-pulse rectifiers and their spectrum

RMS is $\sqrt{3} U_{\mathrm{m}}$. From (1), the RMS of the voltage across the extended winding is equal to $(2-\sqrt{3}) U_{\mathrm{m}}$.

From Fig. 4 and (11), the RMS of current through the extended winding is

$I_{\mathrm{a} 1 \Delta}=I_{\mathrm{b} 1 \Delta}=I_{\mathrm{c} 1 \Delta}=I_{\mathrm{a} 2 \Delta}=I_{\mathrm{b} 2 \Delta}=I_{\mathrm{c} 2 \Delta}=\frac{\sqrt{6}}{6} I_{\mathrm{d} \Delta}$

where $I_{\mathrm{d} \Delta}$ is the load current when using delta-connected autotransformer.

From Fig. 4, (1) and (8), the RMS of the current through the delta-connected winding is 
$I_{1 \Delta}=I_{2 \Delta}=I_{3 \Delta}=\frac{2-\sqrt{3}}{6} I_{\mathrm{d} \Delta}$

Therefore, the $\mathrm{kVA}$ rating of the delta-connected autotransformer is

$$
\begin{aligned}
S_{\text {delta-con-tra }} & =\frac{1}{2}\left[6(2-\sqrt{3}) U_{\mathrm{m}} \frac{\sqrt{6}}{6} I_{\mathrm{d} \Delta}+3 \sqrt{3} U_{\mathrm{m}} \frac{2-\sqrt{3}}{6} I_{\mathrm{d} \Delta}\right] \\
& =\frac{1}{4}(2-\sqrt{3}) \sqrt{3}(2 \sqrt{2}+1) U_{\mathrm{m}} I_{\mathrm{d} \Delta}
\end{aligned}
$$

From (21), the RMS value of the load voltage is calculated as

$U_{\mathrm{d} \Delta}=\frac{\sqrt{3} \sqrt{\pi+3} U_{\mathrm{m}}}{\sqrt{\pi}}$

Substituting (26) into (25) yields

$$
\begin{aligned}
S_{\text {delta-con-tran }} & =\frac{(2-\sqrt{3})(2 \sqrt{2}+1) \sqrt{\pi}}{4 \sqrt{\pi+3}} U_{\mathrm{d} \Delta} I_{\mathrm{d} \Delta} \\
& =18.34 \% U_{\mathrm{d} \Delta} I_{\mathrm{d} \Delta}
\end{aligned}
$$

When using the delta-connected autotransformer, define the load power as

$P_{\Delta}=U_{\mathrm{d} \Delta} I_{\mathrm{d} \Delta}$

From (27) and (28), the kVA rating of the deltaconnected autotransformer accounts for $18.34 \%$ of the load power.

\section{2 kVA rating of wye-connected autotransformer}

From Fig. 3, the voltage across the delta-connected winding is equal to the input phase voltage, and its RMS is $U_{\mathrm{m}}$. From (2), the RMS value of the voltage across the extended winding is equal to $(2-\sqrt{3}) U_{\mathrm{m}}$.

From Fig. 4 and expression (11), the RMS of current through the extended winding of the wye-connected autotransformer also meets (23), that is

$I_{\mathrm{a} 1 \mathrm{Y}}=I_{\mathrm{b} 1 \mathrm{Y}}=I_{\mathrm{c} 1 \mathrm{Y}}=I_{\mathrm{a} 2 \mathrm{Y}}=I_{\mathrm{b} 2 \mathrm{Y}}=I_{\mathrm{c} 2 \mathrm{Y}}=\frac{\sqrt{6}}{6} I_{\mathrm{dY}}$

where $I_{\mathrm{dY}}$ is the load current when using wye-connected autotransformer.

From Fig. 4, expression (2) and (14), the RMS value of the current through the wye-connected winding is

$I_{1 \mathrm{Y}}=I_{2 \mathrm{Y}}=I_{3 \mathrm{Y}}=\frac{(2 \sqrt{3}-3)}{6} I_{\mathrm{dY}}$

Therefore, the kVA rating of the wye-connected autotransformer is

$$
\begin{aligned}
S_{\text {wye-con-tran }} & =\frac{1}{2}\left[3 U_{\mathrm{m}} \frac{(2 \sqrt{3}-3)}{6} I_{\mathrm{dY}}+6(2-\sqrt{3}) U_{\mathrm{m}} \frac{\sqrt{6}}{6} I_{\mathrm{dY}}\right] \\
& =\frac{1+2 \sqrt{2}}{4}(2-\sqrt{3}) \sqrt{3} U_{\mathrm{m}} I_{\mathrm{dY}}
\end{aligned}
$$

From (22), the RMS of the load voltage is

$U_{\mathrm{dY}}=\frac{3 \sqrt{\pi+3} U_{\mathrm{m}}}{2 \sqrt{\pi}}$

Substituting (32) into (31) yields

$$
\begin{aligned}
S_{\text {wye-con-tran }} & =\frac{(2-\sqrt{3})(1+2 \sqrt{2}) \sqrt{\pi}}{2 \sqrt{3} \sqrt{\pi+3}} U_{\mathrm{dY}} I_{\mathrm{dY}} \\
& =21.18 \% U_{\mathrm{dY}} I_{\mathrm{dY}}
\end{aligned}
$$

When using the wye-connected autotransformer, define the load power as

$P_{\mathrm{Y}}=U_{\mathrm{dY}} I_{\mathrm{dY}}$

From (33) and (34), the kVA rating of the wyeconnected autotransformer accounts for $21.28 \%$ of the load power.

From (23) and (29), under the same load current, the RMS of currents through the extended windings of the wye-connected autotransformer is larger than that of the delta-connected autotransformer. Therefore, under the same load power, the $\mathrm{kVA}$ rating of the wye-connected autotransformer is greater than that of the delta-connected autotransformer.

\section{$4 \mathrm{kVA}$ rating of the auxiliary magnetic devices}

IPR and ZSBT are the important auxiliary magnetic devices in MPR using auto-connected transformer. Therefore, it is necessary to calculate their $\mathrm{kVA}$ rating and compare it under the same load power.

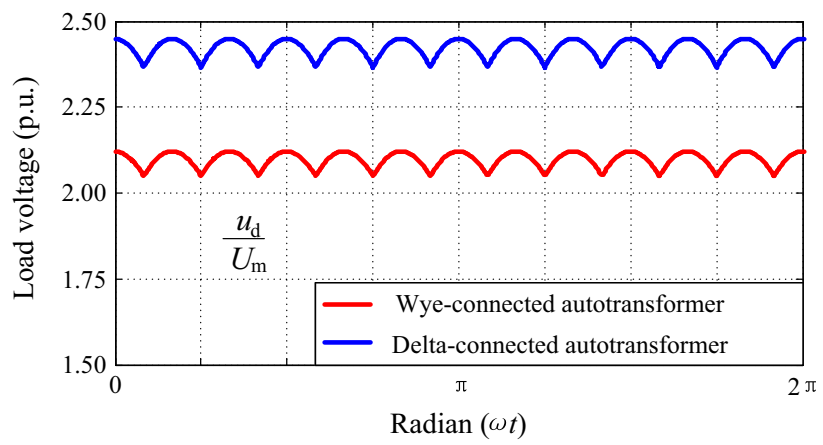

Fig. 6 Load voltages when using different autotransformers 
In Fig. 1, the voltage across IPR can be expressed as

$$
\begin{aligned}
u_{\mathrm{IPR}} & =v_{\mathrm{m} 1 \mathrm{n}}-v_{\mathrm{m} 3 \mathrm{n}}-\left(v_{\mathrm{m} 2 \mathrm{n}}-v_{\mathrm{m} 4 \mathrm{n}}\right) \\
& =v_{\mathrm{m} 1 \mathrm{n}}-v_{\mathrm{m} 2 \mathrm{n}}-\left(v_{\mathrm{m} 3 \mathrm{n}}-v_{\mathrm{m} 4 \mathrm{n}}\right) \\
& =u_{\mathrm{d} 1}-u_{\mathrm{d} 2}
\end{aligned}
$$

where $v_{\mathrm{m} 1 \mathrm{n}}, v_{\mathrm{m} 2 \mathrm{n}}, v_{\mathrm{m} 3 \mathrm{n}}, v_{\mathrm{m} 4 \mathrm{n}}$ are the potentials of points $\mathrm{m} 1$, $\mathrm{m} 2, \mathrm{~m} 3, \mathrm{~m} 4$, respectively.

Substituting (20) into (35), when using the delta-connected autotransformer, the RMS of the voltage across IPR is

$U_{\text {IPR }-\Delta}=\frac{2 \sqrt{3}(2-\sqrt{3}) \sqrt{\pi-3}}{\sqrt{\pi}} U_{\mathrm{m}}$

Similarly, when using wye-connected autotransformer, the RMS of the voltage across IPR is calculated as

$U_{\mathrm{IPR}-\mathrm{Y}}=\frac{3(2-\sqrt{3}) \sqrt{\pi-3}}{\sqrt{\pi}} U_{\mathrm{m}}$

From Fig. 1, the voltage across ZSBT meets

$u_{\mathrm{ZSBT}}=\frac{1}{2}\left(v_{\mathrm{m} 2 \mathrm{n}}-v_{\mathrm{m} 4 \mathrm{n}}\right)$

From Fig. 1, $v_{\mathrm{m} 2 \mathrm{n}}$ and $v_{\mathrm{m} 4 \mathrm{n}}$ meet

$\left\{\begin{array}{l}v_{\mathrm{m} 2 \mathrm{n}}=S_{\mathrm{a} 1}^{\prime \prime} u_{\mathrm{a} 1}+S_{\mathrm{b} 1}^{\prime \prime} u_{\mathrm{b} 1}+S_{\mathrm{c} 1}^{\prime \prime} u_{\mathrm{c} 1} \\ v_{\mathrm{m} 4 \mathrm{n}}=S_{\mathrm{a} 2}^{\prime \prime} u_{\mathrm{a} 2}+S_{\mathrm{b} 2}^{\prime \prime} u_{\mathrm{b} 2}+S_{\mathrm{c} 2}^{\prime \prime} u_{\mathrm{c} 2}\end{array}\right.$

where $S_{\mathrm{a} 1}^{\prime \prime}, S_{\mathrm{b} 1}^{\prime \prime}, S_{\mathrm{c} 1}^{\prime \prime}, S_{\mathrm{a} 2}^{\prime \prime}, S_{\mathrm{b} 2}^{\prime \prime}, S_{\mathrm{c} 2}^{\prime \prime}$ meet

$S_{i 1}^{\prime \prime}=\frac{1}{2}\left(\left|S_{i 1}\right|-S_{i 1}\right)$

where $i=\mathrm{a}, \mathrm{b}, \mathrm{c}$.

Therefore, from (6), (38), (39) and Fig. 4, when using the delta-connected autotransformer, the RMS of the voltage across ZSBT is calculated as

$U_{\mathrm{ZSBT}-\Delta}=\sqrt{\frac{8-3 \sqrt{3}}{2}-\frac{9-3 \sqrt{3}}{\pi}} \frac{U_{\mathrm{m}}}{(\sqrt{3}+1)}$

When using the wye-connected autotransformer, the RMS of the voltage across ZSBT is calculated as

$U_{\mathrm{ZSBT}-\mathrm{Y}}=\sqrt{\frac{8-3 \sqrt{3}}{2}-\frac{9-3 \sqrt{3}}{\pi}} \frac{\sqrt{3}}{2(\sqrt{3}+1)} U_{\mathrm{m}}$

The currents through the IPR and ZSBT are equal to the output currents of the two bridge rectifiers. Therefore, the currents through IPR and ZSBT meet

$$
\left\{\begin{aligned}
I_{\mathrm{IPR}-\mathrm{ZSBT}-\Delta} & =\frac{1}{2} I_{\mathrm{d} \Delta} \\
I_{\mathrm{IPR}-\mathrm{ZSBT}-\mathrm{Y}} & =\frac{1}{2} I_{\mathrm{dY}}
\end{aligned}\right.
$$

Therefore, when using the delta-connected autotransformer, the $\mathrm{kVA}$ rating of IPR is calculated as
$S_{\text {IPR }-\Delta}=\frac{(2-\sqrt{3}) \sqrt{\pi-3}}{2 \sqrt{\pi+3}} U_{\mathrm{d} \Delta} I_{\mathrm{d} \Delta}=2.03 \% U_{\mathrm{d} \Delta} I_{\mathrm{d} \Delta}$

and the kVA rating of IPR when using the wye-connected autotransformer is calculated as

$$
\begin{aligned}
S_{\mathrm{IPR}-\mathrm{Y}} & =\frac{(2-\sqrt{3}) \sqrt{\pi-3}}{2 \sqrt{\pi+3}} U_{\mathrm{dY}} I_{\mathrm{dY}} \\
& =2.03 \% U_{\mathrm{dY}} I_{\mathrm{dY}}
\end{aligned}
$$

When using the delta-connected autotransformer, the $\mathrm{kVA}$ rating of $\mathrm{ZSBT}$ is calculated as

$$
\begin{aligned}
S_{\mathrm{ZSBT}-\Delta} & =\sqrt{\frac{8-3 \sqrt{3}}{2}-\frac{9-3 \sqrt{3}}{\pi}} \frac{\sqrt{\pi}}{\sqrt{\pi+3}} \frac{(3-\sqrt{3})}{6} U_{\mathrm{d} \Delta} I_{\mathrm{d} \Delta} \\
& =6.61 \% U_{\mathrm{d} \Delta} I_{\mathrm{d} \Delta}
\end{aligned}
$$

and the kVA rating of ZSBT when using the wyeconnected autotransformer is calculated as

$$
\begin{aligned}
S_{\mathrm{ZSBT}-\mathrm{Y}} & =\sqrt{\frac{8-3 \sqrt{3}}{2}-\frac{9-3 \sqrt{3}}{\pi}} \frac{\sqrt{\pi}}{\sqrt{\pi+3}} \frac{(3-\sqrt{3})}{6} U_{\mathrm{dY}} I_{\mathrm{dY}} \\
& =6.61 \% U_{\mathrm{dY}} I_{\mathrm{dY}}
\end{aligned}
$$

From (27), (44) and (46), when using the deltaconnected autotransformer, the sum of the kVA rating of the magnetic devices is calculated as

$$
\begin{aligned}
S_{\mathrm{kVA}-\Delta} & =S_{\text {delta-con-tran }}+S_{\mathrm{ZSBT}-\Delta}+S_{\mathrm{IPR}-\Delta} \\
& =26.98 \% U_{\mathrm{d} \Delta} I_{\mathrm{d} \Delta}
\end{aligned}
$$

From (33), (45) and (47), when using the wye-connected autotransformer, the sum of the kVA rating of the magnetic devices is calculated as

$$
\begin{aligned}
S_{\mathrm{kVA}-\mathrm{Y}} & =S_{\text {wye-con-tran }}+S_{\mathrm{ZSBT}-\mathrm{Y}}+S_{\mathrm{IPR}-\mathrm{Y}} \\
& =29.82 \% U_{\mathrm{dY}} I_{\mathrm{dY}}
\end{aligned}
$$

From (36), (37), (41), (42), (44)-(49), the following conclusions are obtained.

1) Under the same input voltages, when using the deltaconnected autotransformer, the voltages across ZSBT and IPR are greater than that of using wye-connected autotransformer, respectively.

2) Under the load power, when using the delta-connected autotransformer, the kVA ratings of ZSBT and IPR are equal to that of using wye-connected autotransformer, respectively.

3) Under the same load power, when using the deltaconnected autotransformer, the $\mathrm{kVA}$ rating of the magnetic devices is less that of using wye-connected autotransformer. 


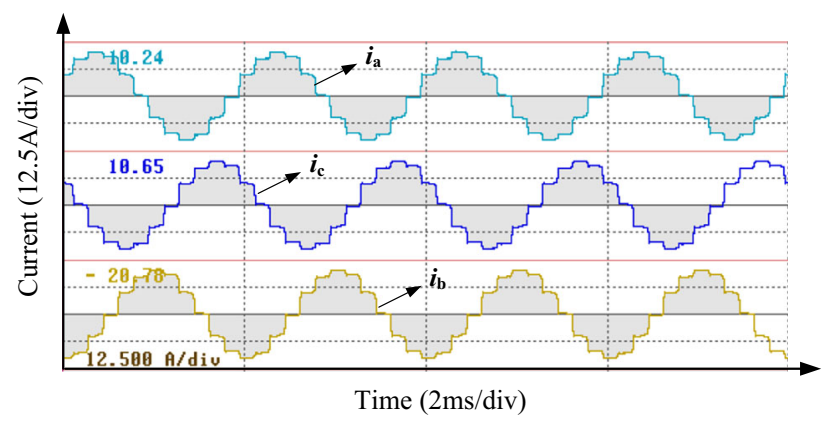

Fig. 7 Input line currents when using the delta-connected autotransformer

\section{Experimental validation}

In order to validate the aforementioned analysis, we designed two 12-pulse rectifiers using delta-connected autotransformer and wye-connected autotransformer, respectively, and carried out the corresponding experiments. The experimental conditions are listed as follows: (1) The RMS value of the three-phase input voltages is 220 $\mathrm{V}$; (2) The load is resistive-inductive load, and the load resistance is $20 \Omega$ in the 12-pulse rectifier using wyeconnected autotransformer, and the load resistance is $30 \Omega$ in the 12-pulse rectifier using delta-connected autotransformer, the load inductance is $15 \mathrm{mH}$.

\subsection{Experimental results of delta-connected autotransformer}

Figure 7 shows the input line current. In Fig. 7, the RMS of the three current are 14.547, 14.519, 14.550 A, respectively; and the THD values of the three currents are $12.81 \%, 12.76 \%, 12.71 \%$, respectively. Because of the

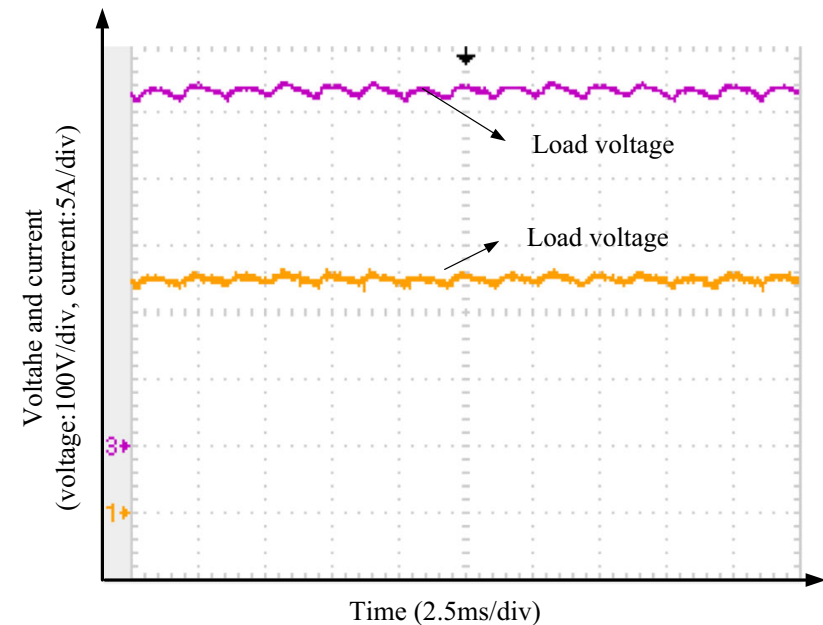

Fig. 8 Load current and load voltage of 12-pulse rectifier using the delta-connected autotransformer effect of the leakage inductance of autotransformer, the THD of the experimental results is less than that of the theoretical results.

Load current and load voltage are illustrated in Fig. 8, and their RMS values are $533 \mathrm{~V}$ and $17.9 \mathrm{~A}$, respectively. Therefore, the load power is $9540.7 \mathrm{~W}$.

Figure 9a shows the currents through the delta-connected windings, and their RMS values are 0.911, 0.913, $0.906 \mathrm{~A}$, respectively. Figure $9 \mathrm{~b}$ shows the voltages across and currents through the extended windings, and the RMS values of the two voltages are $58.38,59.09 \mathrm{~V}$, respectively; the RMS values of the two currents are 7.088 A, 7.144 A, respectively.

Assume the winding configuration of autotransformer is symmetrical, the kVA rating of the delta-connected autotransformer can be calculated as

$$
\begin{aligned}
S_{\text {Auto- } \Delta}= & \frac{1}{2} \times 380 \times(0.911+0.913+0.906) \\
& +\frac{1}{2} \times 3 \times 58.38 \times 7.088+\frac{1}{2} \times 3 \times 59.09 \times 7.144 \\
= & 1772.6 \mathrm{VA}
\end{aligned}
$$

Therefore, the kVA rating is about $18.57 \%$ of the load power.

Figure 10 shows the voltages across the IPR and ZSBT. The RMS values of the two voltages are $47.8,35.8 \mathrm{~V}$, respectively.

Assume that the system is symmetrical, output currents of the two diode bridge rectifiers are equal. From Fig. 10, the $\mathrm{kVA}$ ratings of ZSBT and IPR are calculated as

$S_{\text {ZSBT }-\Delta}=\frac{1}{2} \times 4 \times 35.8 \times 8.95=640.82 \mathrm{VA}$

$S_{\text {IPR- } \Delta}=\frac{1}{2} \times 47.8 \times 8.95=213.91 \mathrm{VA}$

Therefore, the kVA rating of ZSBT is $6.72 \%$ of load power, and the kVA rating of IPR is $2.24 \%$ of load power.

From (51), (52) and (53), it is obtained that the sum of the kVA ratings of the magnetic devices are 2627.33 VA, which is account for $27.54 \%$ of load power.

\subsection{The experimental results of the wye-connected autotransformer}

Figure 11 shows the input line current. In Fig. 11, the RMS of the three current are 16.069, 16.053, 16.079 A, respectively; and the THD values of the three currents are $12.92 \%, 12.73 \%, 12.67 \%$, respectively. Similarly, because of the effect of the leakage inductance of autotransformer, the THD of the experimental results is less than that of the theoretical results. 


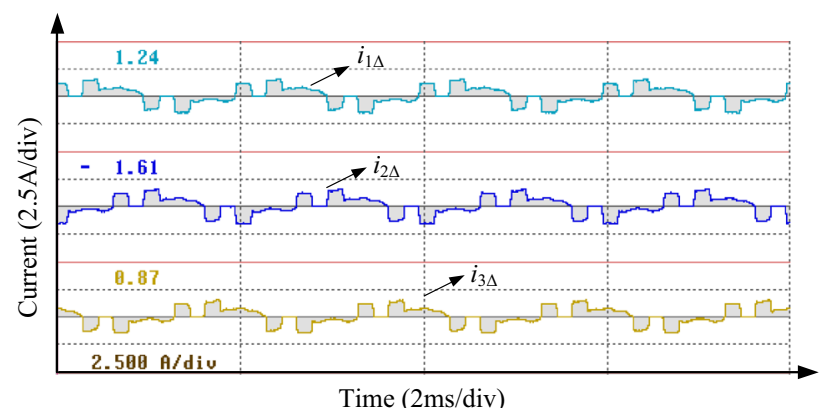

(a) Currents through the delta-connected windings

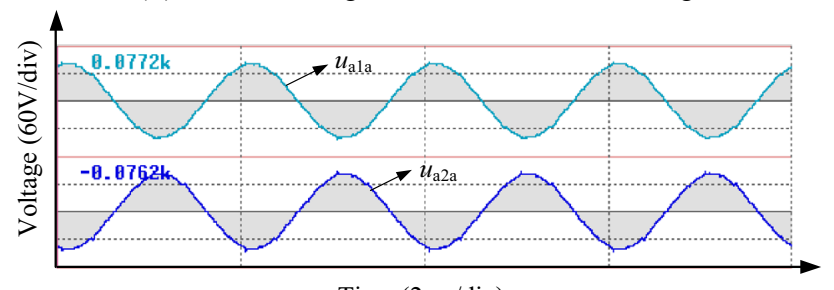

(b) Voltages across the extended windings.

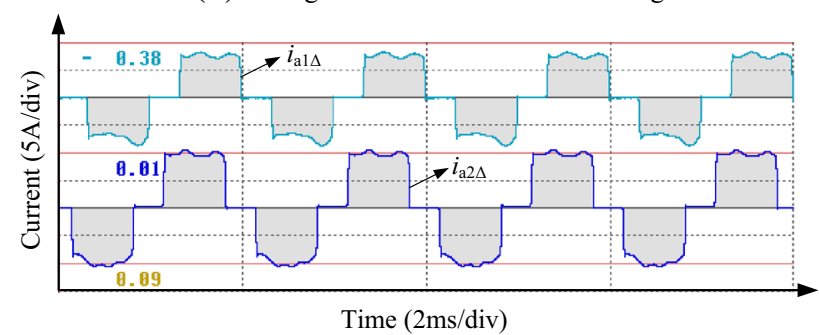

(c) Currents through the extended windings.

Fig. 9 Voltages across and currents through the windings of the delta-connected autotransformer

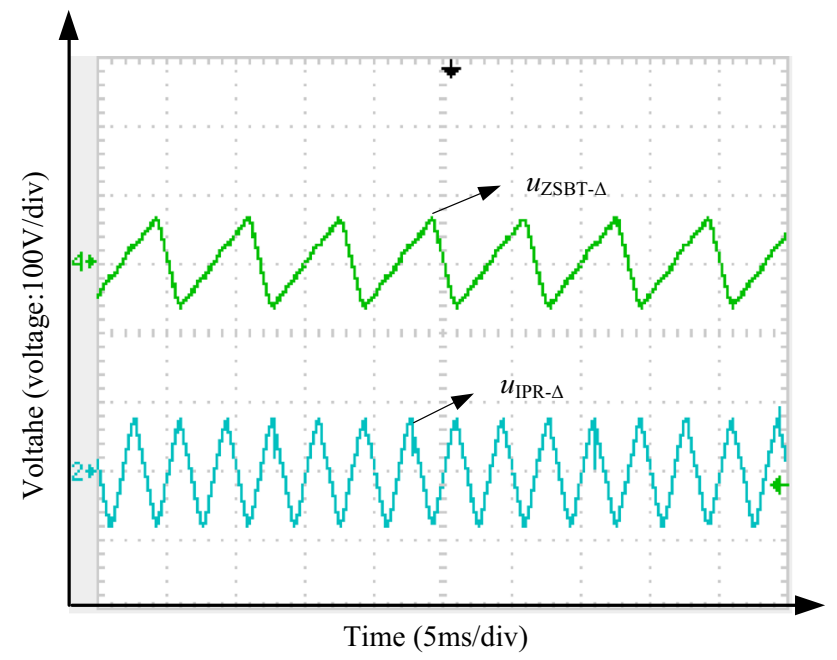

Fig. 10 Voltages across ZSBT and IPR when using the deltaconnected autotransformer

Load current and load voltage are shown in Fig. 12, and their RMS values are $462 \mathrm{~V}$ and $22.4 \mathrm{~A}$, respectively. Therefore, the load power is about $10348.8 \mathrm{~W}$.

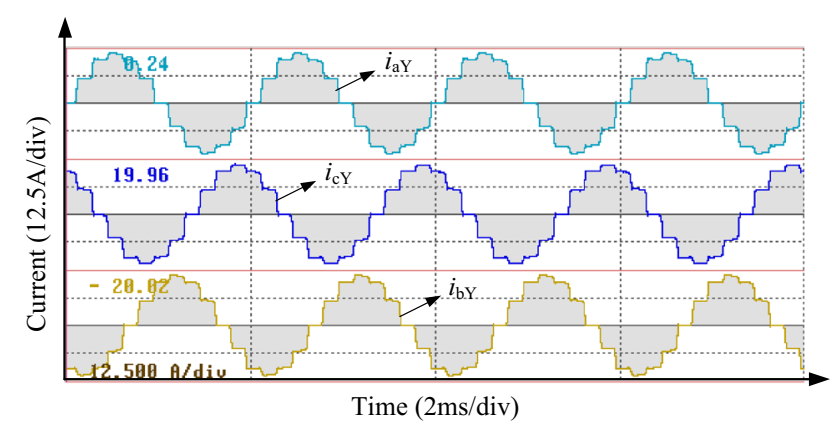

Fig. 11 Input line currents when using wye-connected autotransformer

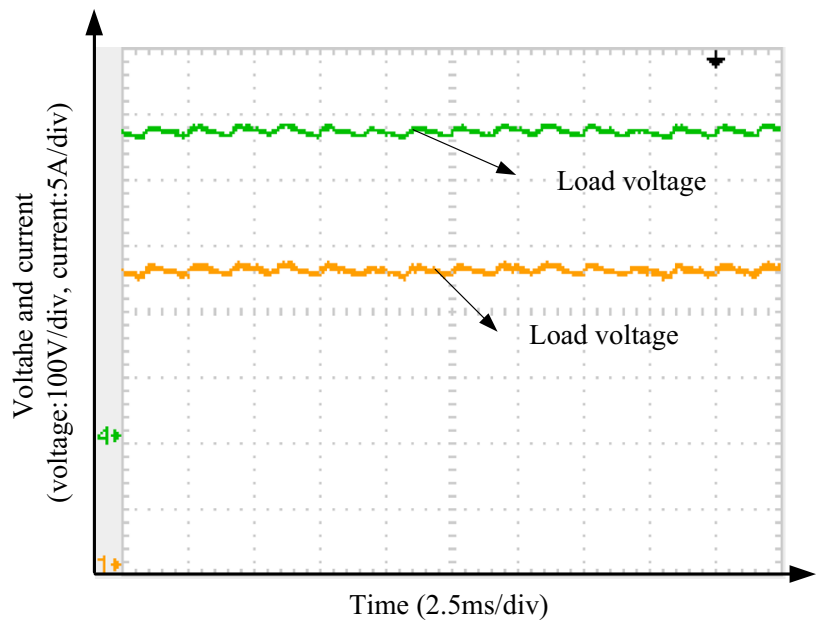

Fig. 12 Load voltage and load current of 12-pulse rectifier using the wye-connected autotransformer

Figure 13a shows the currents through the wye-connected windings, and the RMS values of the currents are $1.668,1.678,1.708$ A, respectively. Figure $13 \mathrm{~b}$ shows the voltages across and the currents through the extended windings, and their RMS values are 60.16 and $59.21 \mathrm{~V}$, and the RMS values of the currents are 9.214 and $9.105 \mathrm{~A}$.

From Fig. 13, the kVA rating of the wye-connected autotransformer is

$$
\begin{aligned}
S_{\text {Auto-Y }}= & \frac{1}{2} \times 220 \times(1.668+1.678+1.708) \\
& +\frac{1}{2} \times 3 \times 60.16 \times 9.214+\frac{1}{2} \times 3 \times 59.21 \times 9.105 \\
= & 2196.072 \mathrm{VA}
\end{aligned}
$$

The kVA rating of the autotransformer accounts for about $21.22 \%$ of the load power.

Figure 14 shows the voltages across the IPR and ZSBT. The RMS values of the two voltages are 42.4 and $30.3 \mathrm{~V}$, respectively. 


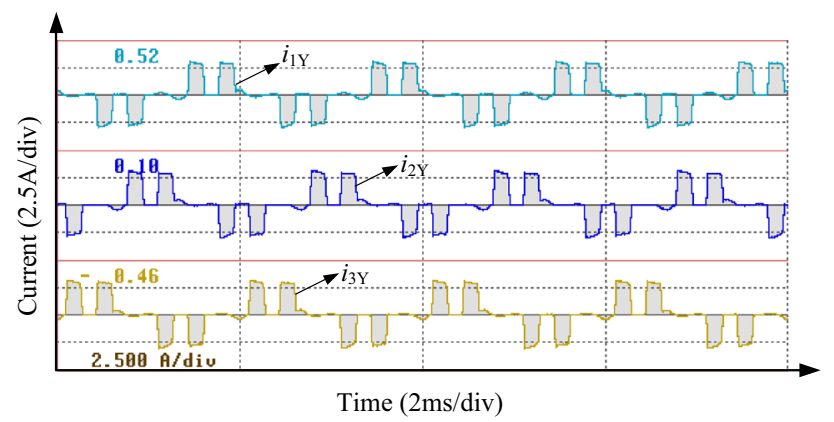

(a) Currents through the wye-connected windings.

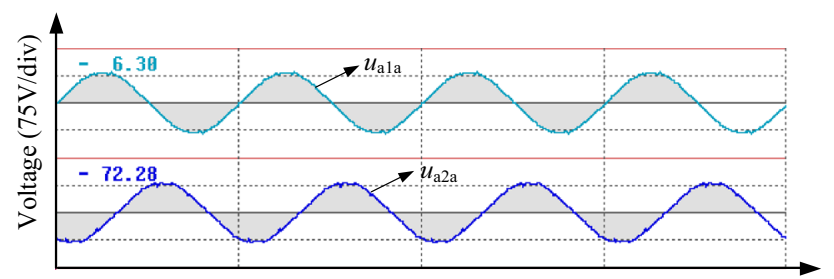

Time ( $2 \mathrm{~ms} / \mathrm{div})$

(b) Voltages across the extended windings.

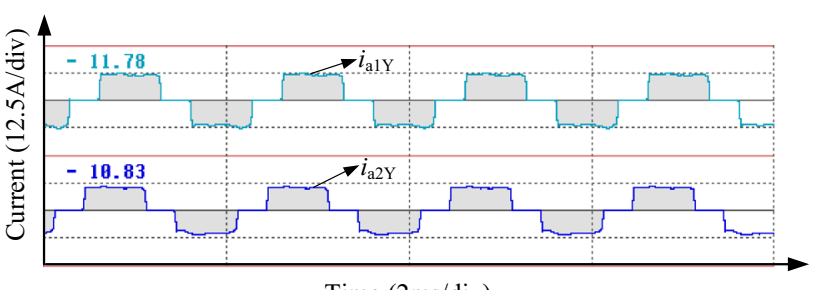

(c) Currents through the extended windings.

Fig. 13 Voltage across and current through the winding of the wyeconnected autotransformer

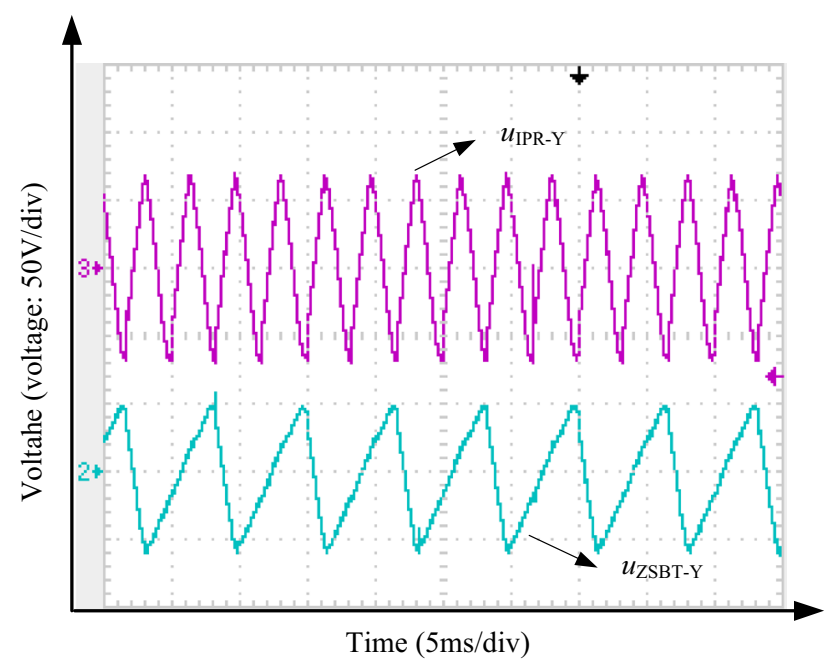

Fig. 14 Voltages across ZSBT and IPR when using the wyeconnected autotransformer
From Figs. 13 and 14, the kVA ratings of ZSBT and IPR are calculated as

$S_{\text {ZSBT-Y }}=\frac{1}{2} \times 4 \times 30.3 \times 11.2=678.72 \mathrm{VA}$

$S_{\text {IPR-Y }}=\frac{1}{2} \times 42.4 \times 11.2=153.4 \mathrm{VA}$

Therefore, the kVA rating of ZSBT is $6.56 \%$ of load power, and the kVA rating of IPR is $2.29 \%$ of load power.

From (54), (55) and (56), it is obtained that the sum of the kVA ratings of the magnetic devices are 3028.192 VA, which is account for $29.26 \%$ of load power.

From above theoretical analysis and experimental results, the comprehensive comparison of the 12-pulse rectifier when using delta- and wye-connected autotransformer is listed in Table 1.

\section{Conclusion}

This paper compares the two 12-pulse rectifiers using delta-connected autotransformer and wye-connected autotransformer. From the theoretical analysis and experimental results, some conclusions are obtained as follows:

1) Both of the input line currents of the two 12-pulse rectifiers contains 12 steps, and both of the load voltage of the two 12-pulse rectifiers contains 12 pulses. Therefore, the two 12-pulse rectifiers are the same power quality.

2) Under the same load current, when using the deltaconnected autotransformer, the input line current is greater than that of using the wye-connected autotransformer.

3) Because of the delta-connected autotransformer and wye-connected autotransformer operating under stepup and step-down condition, respectively, under the same input voltages, the load voltage when using the delta-connected autotransformer is greater than that of using the wye-connected autotransformer.

4) Under the same load power, the kVA rating of the delta-connected autotransformer is less than that of the wye-connected autotransformer.

5) Under the same input voltages, when using deltaconnected autotransformer, the voltages across the ZSBT and IPR are greater than that of using wyeconnected autotransformer, respectively.

6) Under the load power, when using delta-connected autotransformer, the kVA ratings of the ZSBT and IPR are equal to that of using the wye-connected autotransformer, respectively. 
Table 1 Comprehensive comparison of the 12-pulse rectifier using delta- and wye- connected autotransformer

\begin{tabular}{lll}
\hline Item & Theoretical value & Experimental results \\
\hline $\mathrm{kVA}$ of $\Delta$-connected autotransformer & $18.34 \%$ of load power & $18.6 \%$ of load power \\
$\mathrm{kVA}$ of Y-connected autotransformer & $21.18 \%$ of load power & $21.2 \%$ of load power \\
$\mathrm{kVA}$ of IPR using the $\Delta$-connected autotransformer & $2.03 \%$ of load power & $2.24 \%$ of load power \\
$\mathrm{kVA}$ of IPR using Y-connected autotransformer & $2.03 \%$ of load power & $2.29 \%$ of load power \\
$\mathrm{kVA}$ of ZSBT using $\Delta$-connected autotransformer & $6.61 \%$ of load power & $6.72 \%$ of load power \\
$\mathrm{kVA}$ of ZSBT using Y-connected autotransformer & $6.61 \%$ of load power & $6.56 \%$ of load power \\
\hline
\end{tabular}

7) Under the same load power, when using deltaconnected autotransformer, the $\mathrm{kVA}$ rating of the magnetic devices is less that of using wye-connected autotransformer.

Acknowledgment This work was supported by National Natural Science Foundation of China (No. 51307034), in part by the Natural Science Foundation of Shandong Province (No. ZR2013EEQ002).

Open Access This article is distributed under the terms of the Creative Commons Attribution 4.0 International License (http:// creativecommons.org/licenses/by/4.0/), which permits unrestricted use, distribution, and reproduction in any medium, provided you give appropriate credit to the original author(s) and the source, provide a link to the Creative Commons license, and indicate if changes were made.

\section{References}

[1] Singh B, Gairola S, Singh BN et al (2008) Multi-pulse AC-DC converters for improving power quality: a review. IEEE Trans Power Electron 23(1):260-281

[2] Hamad MS, Masoud MI, Williams BW (2014) Medium-voltage 12-pulse converter: output voltage harmonic compensation using a series APF. IEEE Trans Ind Electron 61(1):43-52

[3] Ding GQ, Gao F, Zhang S et al (2014) Control of hybrid AC/DC microgrid under islanding operational conditions. J Mod Power Syst Clean Energy 2(3):223-232. doi:10.1007/s40565-0140065-Z

[4] Bai SZ, Lukic SM (2013) New method to achieve AC harmonic elimination and energy storage integration for 12-pulse diode rectifiers. IEEE Trans Ind Electron 60(7):2547-2554

[5] Gong WM, Hu SJ, Shan M et al (2014) Robust current control design of a three phase voltage source converter. J Mod Power Syst Clean Energy 2(1):16-22. doi:10.1007/s40565-014-0051-5

[6] Yang SY, Meng FG, Yang W (2010) Optimum design of interphase reactor with double-tap changer applied to multipulse diode rectifier. IEEE Trans Ind Electron 57(9):3022-3029

[7] Paice DA (1996) Power electronic converter harmonic multipulse methods for clean power. IEEE Press, New York

[8] Sun J, Bing ZH, Karimi KJ (2009) Input impedance modeling of multipulse rectifiers by harmonic linearization. IEEE Trans Power Electron 24(12):2812-2820

[9] Fernandes RC, da Silva PO, de Seixas FJM (2011) A family of autoconnected transformers for 12- and 18-pulse convertersgeneralization for delta and wye topologies. IEEE Trans Power Electron 26(7):2065-2078
[10] Wen JP, Qin HH, Wang SS, et al (2012) Basic connections and strategies of isolated phase-shifting transformers for multipulse rectifiers: a review. In: Proceedings of the 2012 Asia-Pacific symposium on electromagnetic compatibility (APEMC'12), Singapore, 21-24 May 2012, pp 105-108

[11] Singh B, Garg V, Bhuvaneswari G (2007) A novel T-connected autotransformer-based 18-pulse AC-DC converter for harmonic mitigation in adjustable-speed induction-motor drives. IEEE Trans Ind Electron 54(5):2500-2511

[12] Singh B, Bhuvaneswari G, Garg V (2006) T-connected autotransformer-based 24-pulse AC-DC converter for variable frequency induction motor drives. IEEE Trans Energy Convers 21(3):663-672

[13] Meng FG, Yang W, Yang SY (2013) Effect of voltage transformation ratio on the kilovoltampere rating of delta-connected autotransformer for 12-pulse rectifier system. IEEE Trans Ind Electron 60(9):3579-3588

[14] Wu FJ, Feng F, Luo LS et al (2015) Sampling period online adjusting-based hysteresis current control without band with constant switching frequency. IEEE Trans Ind Electron 62(1):270-277

Fangang MENG was born in Shandong, China, in 1982. He received the B.S degree in thermal energy and power engineering in 2005, and received M.S. degree and Ph.D degree in electrical engineering in 2007 and 2011, respectively, from Harbin Institute of Technology, Harbin, China. His research interests include harmonic detection, stability analysis of converter, high power rectification.

Lei GAO was born in Hebei, China, in 1982. She received the B.S. degree, M.S. degree and Ph.D degree in electrical engineering from Harbin Institute of Technology, Harbin, China, in 2005, 2007 and 2012, respectively. Her current research interests include power electronics and motor drives.

Wei YANG was born in Heilongjiang, China, in 1978. He received the B.S. degree, M.S. degree and Ph.D degree in electrical engineering from Harbin Institute of Technology, Harbin, China, in 2001, 2005 and 2010, respectively. His current research interests include power electronics and motor drives.

Shiyan YANG was born in Heilongjiang, China, in 1962. He received the B.S and M.S degrees in electrical engineering, in 1984 and 1989, respectively, from the Harbin Institute of Technology. And he received Ph.D. degree in welding engineering in 1998. He is currently a professor and supervisor for Doctoral Candidates with Harbin Institute of Technology, Harbin, China. He has published over 60 papers. His research interests include high-power special type power supply and its application, energy storage system and its equilibrium, fundamental theory of finity power supply drive and key commonsense problem. 